\title{
Reconstitution, age estimation and expression of the Human Endogenous Retrovirus KI I 3 with its original sequence present at the time of integration
}

\author{
Norbert Bannert*1, Nadine Beimforde ${ }^{1,2}$, Kirsten Hanke ${ }^{1}$, Marc Reudelsterz ${ }^{1}$, \\ Oliver Hohn ${ }^{1}$ and Reinhard Kurth ${ }^{1}$
}

Address: ${ }^{1}$ Robert Koch-Institute, ZBS4, 13353 Berlin, Germany and ${ }^{2}$ Charité-Universitätsmedizin Berlin, 12203 Berlin, Germany

* Corresponding author

from Frontiers of Retrovirology: Complex retroviruses, retroelements and their hosts

Montpellier, France. 2I-23 September 2009

Published: 24 September 2009

Retrovirology 2009, 6(Suppl 2):P5 doi:10.1 I86/1742-4690-6-S2-P5

This abstract is available from: http://www.retrovirology.com/content/6/S2/P5

(c) 2009 Bannert et al; licensee BioMed Central Ltd.

\section{Background}

Human endogenous retroviruses (HERVs) are remnants of infectious exogenous retroviruses that invaded the germ line of human ancestors and have since been amplified and vertically transmitted. HERV-K113, a provirus present in about $15 \%$ of humans is one of the most complete HERV-K(HML-2) elements known with open reading frames for all viral proteins. Nevertheless, it carries inactivating postinsertional mutations.

\section{Results and conclusion}

By aligning HERV-K113 with related human specific HERV-K elements, we localized 26 putative non-synonymous postinsertional mutations and reversed them by site-directed mutagenesis to reconstitute the original protein sequence. Using this approach, it was possible to reestablish reverse transcriptase activity, particle assembly as well as incorporation and fusogenic function of the envelope protein. Cell lines transfected with a plasmid expressing the reconstituted HERV-K113 produced and released C-type-like particles and reverse transcriptase activity. Protein expression and virus production was significantly enhanced by partial codon-optimization facilitating functional studies on the envelope protein and structural studies on viral morphology. Based on over 20 sequenced HERV-K113 ethnogeographic variants, their sequence variation and phylogeny of the postinsertional mutations will be presented which indicates an older age of this pro- virus and more frequent gene conversion events than expected. 